\title{
Numerical Simulation and Experimental Testing of Two-axle Chassis of Low-floor Trams
}

\section{Tomáš Kalina, Petr Heller, Zdeněk Chval, František Sedláček, Michal Kř́ižek, Lukáš Bartoň}

Regional Technological Institute, Faculty of Mechanical Engineering, University of West Bohemia, 30614 Pilsen. Czech Republic. E-mail: tkalina@rti.zcu.cz, pheller@rti.zcu.cz, zdchval@rti.zcu.cz, fsedlace@rti.zcu.cz, krizek4@rti.zcu.cz, bartonlk@rti.zcu.cz

This paper deals with numerical simulations and with experimental testing of chassis of low-floor trams. This chassis was designed with respect to low-floor construction, low weight, good driveability of a tram and with respect to fulfillment of standards and regulations. The chassis is in a numerical simulation burdened by load conditions according to EN 13749:2011 even during an experimental testing. The simulation is performed using the FEM Nastran solver implemented in the CAD system Siemens NX 11. Based on FEA the locations for strain gauges during testing were found. A total number of 40 strain gauges were used to measure the strain which was then recalculated to uniaxial stress. The testing was performed on hydraulic test bench Inova. The results of FEA and of an experimental testing were compared.

Keywords: tram, chassis, low-floor tram, FEA, experimental testing

\section{Introduction}

It is an Europe-wide trend to make traveling with the public transport easier for people with reduced mobility (elderly, disabled people or people with baby strollers). The solution of how to achieve this is gradual exchange of classical vehicles with low-floor vehicles which have the floor almost in plain with the platform, it means that for entering the vehicle only one step is necessary. It is necessary to adapt the concept of the chassis to the design of a low-floor tram. The chassis for the low-floor tram is designed with respect to the low-floor construction, low weight and good driveability.

\section{Description of a structure and load definition}

\subsection{A chassis design}

The chassis for a low-floor tram vehicles are their important construction structures. A rotary chassis and, in addition, low-floor chassis are technically challenging. Four years ago, as a part of master's thesis [4] such a chassis was designed standard track with a non-standard system of a primary suspension and a two-wheel guiding being chosen. Figure 1 (left) shows a new conception of chassis. Our industrial partners came up with the requirement of a narrow-track chassis which is technically more difficult. The gained experience from the chassis design for the standard track was applied to the narrow-track chassis design. Figure 1 (right) shows the final form of the narrow-track chassis for low-floor tram.

For each vehicle, one of the important parameters is its own weight. Especially with trams that are taking off every 2 to 4 minutes this parameter becomes more serious. The target of the design is the chassis frame weighing $460 \mathrm{~kg}$, while normal frames are around $590 \mathrm{~kg}$.
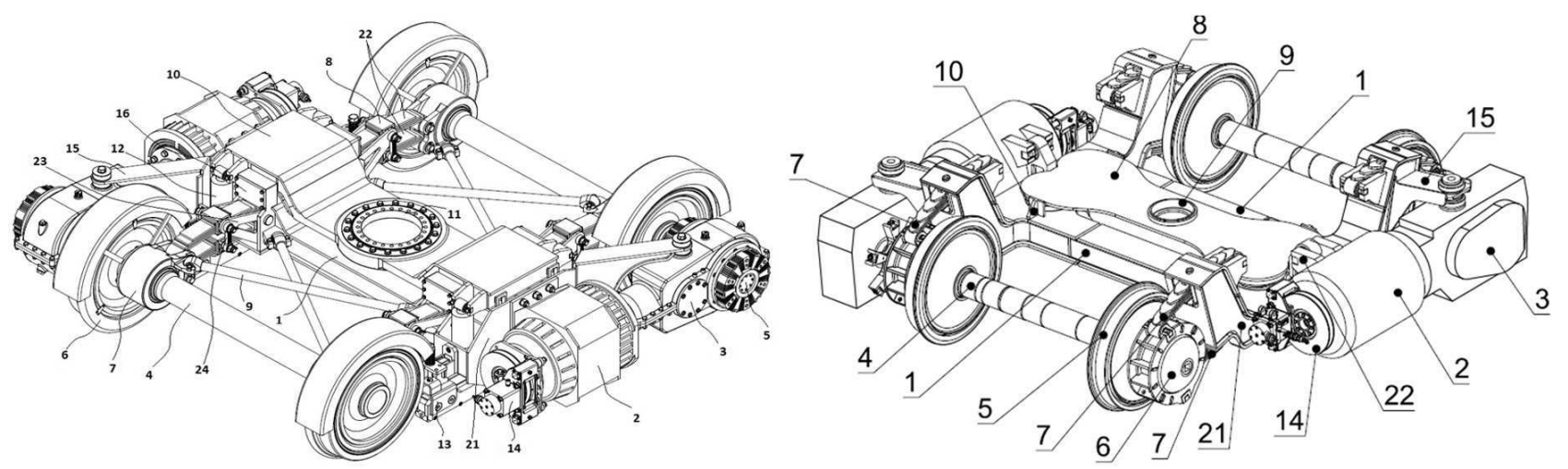

Fig. 1 Rotary low-floor trams chassis with standard track and with traction drives (left) [4] and with narrow-track (right)

\subsection{Description of the structure}

The two-axle chassis consists of a chassis frame, eight leaf springs of a primary suspension and two wheelsets. The frame is a sheet-metal weldment that has two crossbars and two longitudinal members passing through the suspension bracket. In the frame there are two niches for securing the secondary suspension. On the side of the frame there are welded brackets with meshes in which the gearboxes are attached. Two engines are located in two diagonal corners. The leaf springs are rotationally mounted at one end on the brackets, at the other end they are rotationally mounted on the bearing housing. The center 
of the spring supports the chassis frame and allows movement in the direction of travel. Figure 2 shows the prototype of rotary low-floor trams chassis with narrow- track.

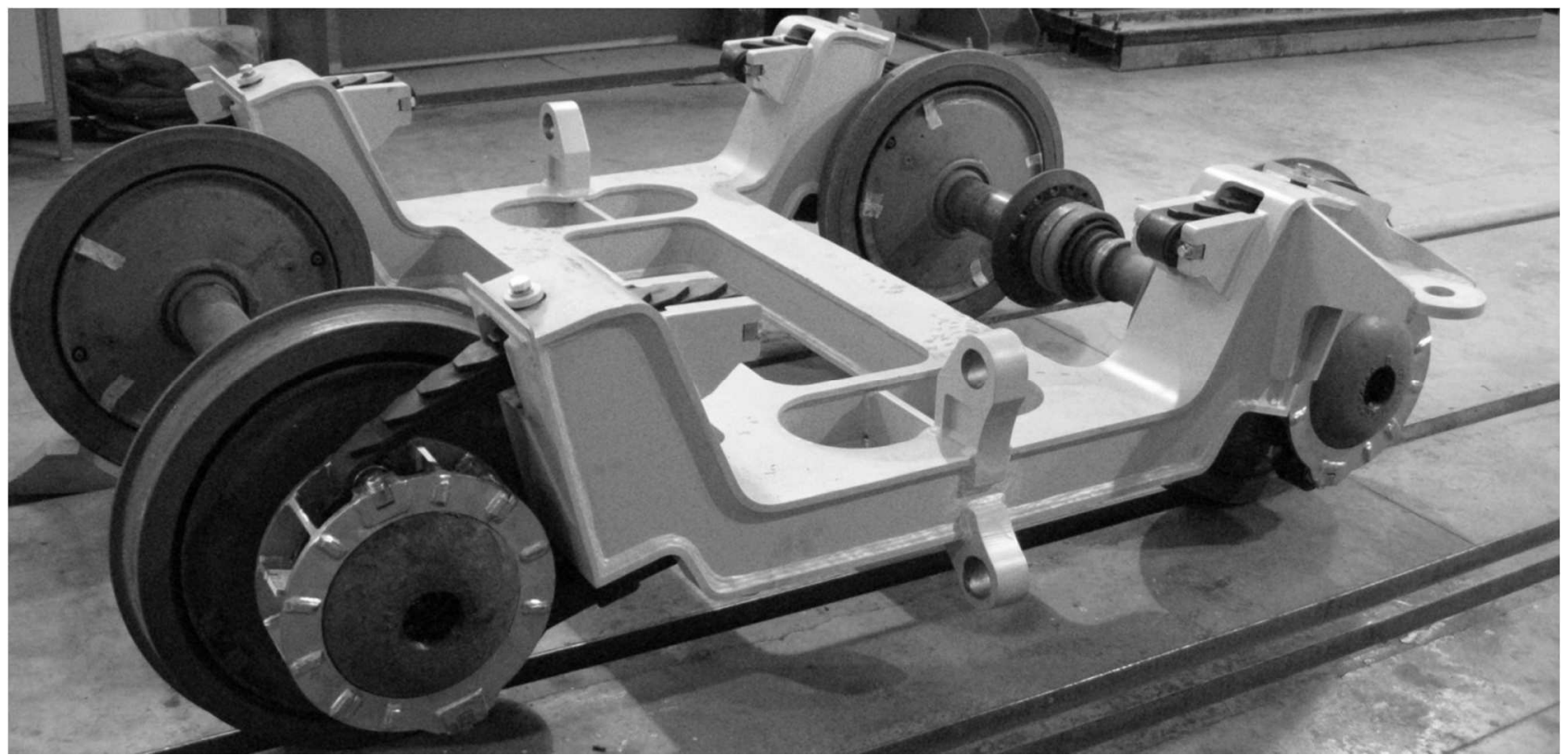

Fig. 2 Functional sample FV 007/2017/21200 - chassis frame, primary suspension and a two-wheel guiding being chosen

\subsection{Specification of load according to the standard}

The EN 13749:2011 [3] norm specifies the method for the design of chassis frames for railway applications, including the way they are evaluated. Figure 3 showes used coordinate system for calculations.

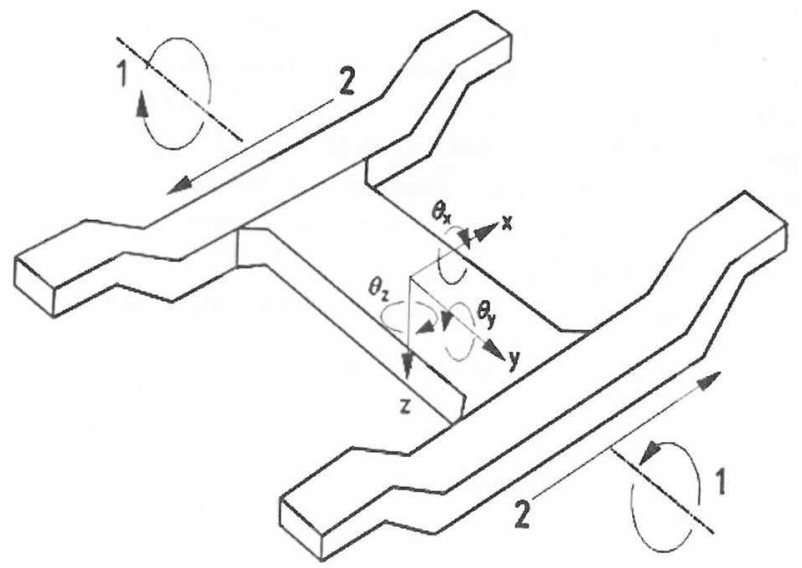

Fig. 3 Coordinate system of chassis according to EN 13749:2011 [3]

\section{Used indexes}

ZC - Vertical axis

$\mathrm{N}$ - Normal operational load

E - Exceptional load

S/C - Straight and curved track

$\mathrm{T}$ - turnout

i - generalized record of indexes (subttitution for $\mathrm{N}$, E)

j - generalized record of indexes (subttitution for S/C,

\section{Input load values}

This low-floor tram has 3 chassis in total.

The weight of an empty tram: $\mathrm{m}_{\mathrm{p}}=29500 \mathrm{~kg}$

The weight of fully-loaded tram: $m_{1}=42800 \mathrm{~kg}$

The weight of a vehicle in an operational order for one chassis: $\mathrm{M}_{\mathrm{V}}=10000 \mathrm{~kg}$

The weight of chassis: $\mathrm{m}^{+}=3600 \mathrm{~kg}$

The standard load for one chassis $\left(4\right.$ persons $\left./ \mathrm{m}^{2}\right): \mathrm{P}_{\mathrm{N}}=$ $2200 \mathrm{~kg}$

The exceptional load for one chassis $\left(8\right.$ persons $\left./ \mathrm{m}^{2}\right)$ : $\mathrm{P}_{\mathrm{E}}=4400 \mathrm{~kg}$

The relative wheel load : $c=104 \%$

The vertical acceleration overload values for different load states

Normal operational load - straight and curved track:

$$
a_{z c_{N-S / C}}=1,2 \frac{\mathrm{m}}{\mathrm{s}^{2}}
$$

Normal operational load - turnout:

$$
a_{z c_{N-T}}=2,4 \frac{\mathrm{m}}{\mathrm{s}^{2}}
$$

Exceptional load - straight and curved track:

Exceptional load - turnout:

$$
a_{z c_{E-S / C}}=1,6 \frac{\mathrm{m}}{\mathrm{s}^{2}}
$$

$$
a_{z c_{E-T}}=3,2 \frac{m}{s^{2}}
$$

Calculation of a weight load according to EN 13749:2011, category B-III and B-IV

1) Normal operational load

$$
\begin{gathered}
\boldsymbol{m}_{N}=\frac{\left(M_{v}+P_{N}\right) c}{100}-\boldsymbol{m}^{+} \\
\boldsymbol{m}_{N}=\mathbf{9 0 8 8}[\mathrm{kg}]
\end{gathered}
$$


2) Exceptional load

$$
\begin{gathered}
m_{E}=\frac{\left(M_{v}+P_{E}\right) c}{100}-m^{+} \\
m_{E}=11376[\mathrm{~kg}]
\end{gathered}
$$

3) Loading forces (generalized record of equation)

$$
F_{Z c_{i j}}=m_{i}\left(g+a_{Z c_{i j}}\right)[N],
$$

Tab. 1 Resulting loading forces [N]

\begin{tabular}{|l|c|c|}
\cline { 2 - 3 } \multicolumn{1}{c|}{} & $\begin{array}{c}\text { Straight and } \\
\text { curved track }\end{array}$ & Turnout \\
\hline $\begin{array}{l}\text { Normal ope- } \\
\text { rational load }\end{array}$ & 100059 & 110964 \\
\hline $\begin{array}{l}\text { Exceptional } \\
\text { load }\end{array}$ & 129800 & 148001 \\
\hline
\end{tabular}

\section{Model For Numerical Calculations}

\section{Simplification of geometry}

The calculation model of the frame was simplified to one-quarter, asymmetry with the load of the engine was neglected (see Fig. 4). The whole frame was connected into one whole without weld modeling. It was believed that the welds were perfectly executed and the individual components were completely connected. The calculation is focused on the frame of chassis and therefore the whole axle, the helical springs of secondary suspension, the load of a motor and the gearbox, the pins for the attachement of the leaf springs in the calculation model are simplified.

The computational model of frame is meshed by 3D tetrahedral with between-nodes (elements type CTETRA(10)) of average size $8 \mathrm{~mm}$ and linear brick emelents (type CHEXA(8)) of average size 4 and $6 \mathrm{~mm}$ [5]. The computational model consists of over 580000 elements. An example of the mesh is shown in Figure 4.

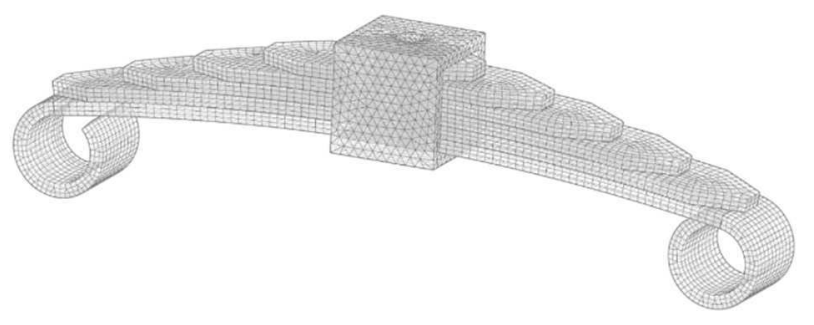

Fig. 4 Specimen of used mesh

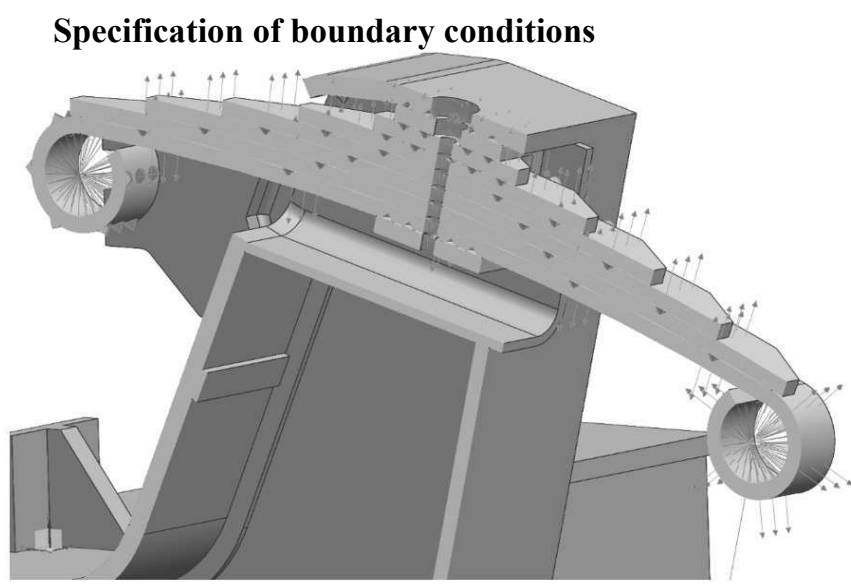

Fig. 5 Boundary conditions - cut of spring and pins attached at the ends of the spring
The computational model of frame of the tram chassis was simplified to the quarter of a frame, that was why a symmetry condition was entered in the plane of the cut. The axles were replaced by the boundary condition. The axle of the axis with the ends of the leaf springs were connected by a pair of 1D BEAM type elements. In the axle of the axis there was applied a boundary condition that allows the vertical plane to move and rotate around the axle axis. The gearbox was replaced by a point in a place of gravity of a gearbox and this point was connected to the meshes where the gearbox was attached by means of the 1D BEAM elements. The pins for attaching leaf springs to the frame were replaced by RBE2 type rigid rosettes (point to face). The stiffness of the silentblocks was neglected, because it is insignificant to the stiffness of steel springs. The connection of the pin and the end of the spring was done by Manual Coupling, where the mutual rotation around the pin axis was allowed. The individual leaves of the leaf spring were separated bodies between which the condition of type contact was set. The contact was also set between the leaves of the spring and a sleeve. The pin passing through the sleeve and the spring leaves was replaced by a 1D BEAM element. The top end of the BEAM was attached to the frame via the Manual Coupling function where it was possible to rotate around the $\mathrm{XC}$ axis and shift the springs towards the frame in the $\mathrm{YC}$ direction (the direction of travel). Directions $\mathrm{XC}$ and $\mathrm{YC}$ are shown in Figure 3. Figures 5 and 6 shows boundary conditions applied on computational model.

\section{Load forces}

The main load from the tram body was applied to the contact surfaces of the helical springs. The size of the load force corresponds to the values in Tab. 1. The motor weight was applied to the silentblock contact surface. The weight of the gearbox was applied to its center of gravity on the simplified arms. Figure 6 shows load forces applied on computational model.

\section{Material data}

The task was solved as linear structural analysis. The material of the frame is steel S355NL, with the yield strength $R_{e}=355 \mathrm{MPa}$. The material of the leaf springs is steel $56 \mathrm{SiCr} 7$ (EN 10089) with the yield strength $R_{e}=$ $1350 \mathrm{MPa}$. Both steel have a common Young's modulus $E=210 \mathrm{GPa}$ and Poissons Ratio $v=0.288$ [6].

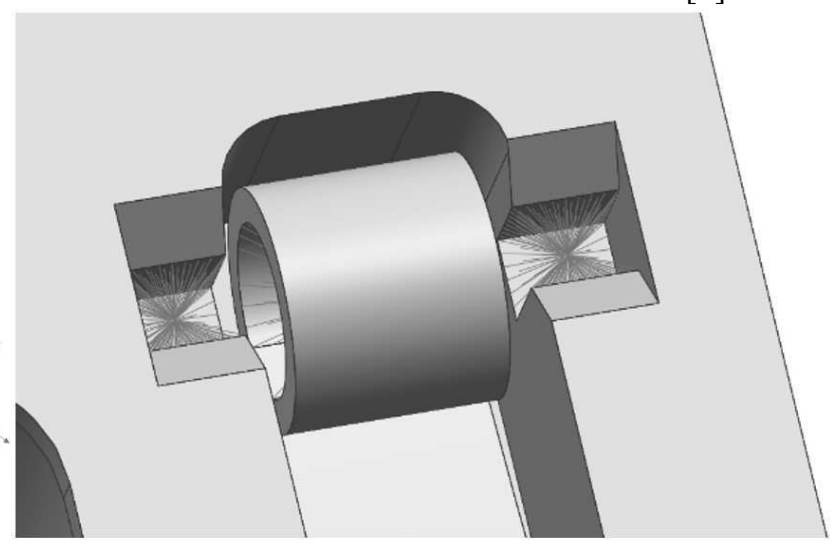




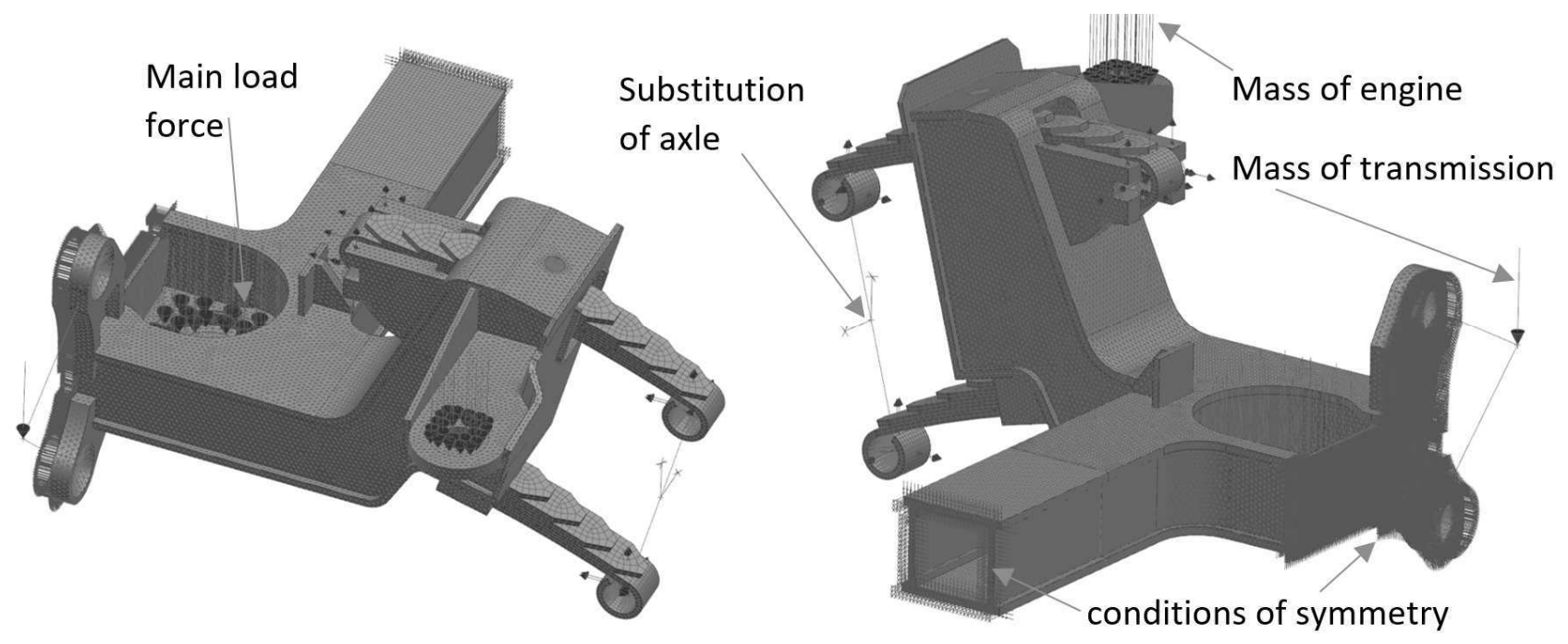

Fig. 6 Application of load forces and boundary conditions

This concept is possible with the CAD and FEM approaches similar to [10][11][12] [13].

\section{Results from fem analysis}

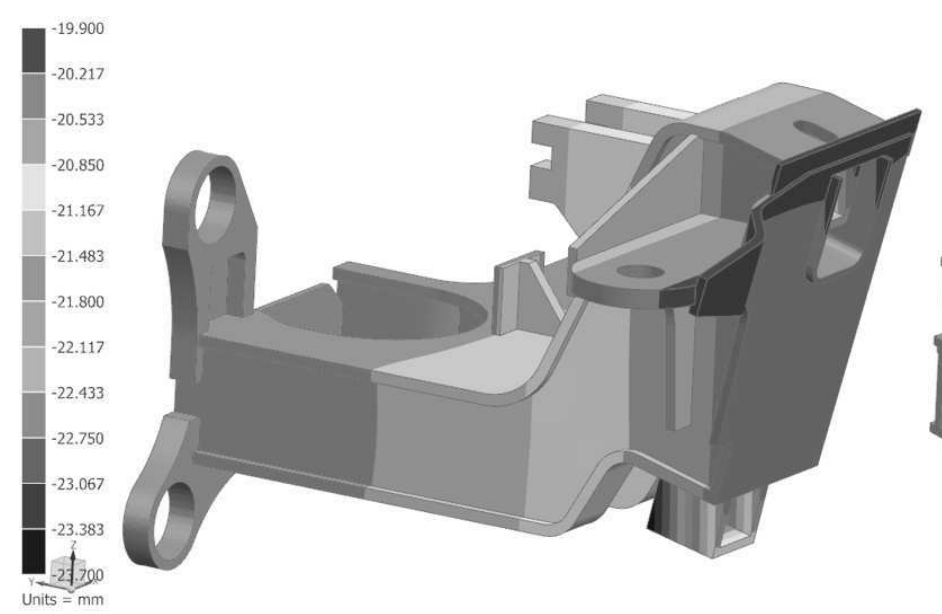

Figure 7 shows results of displacement in the Z-direction [mm]. Figures 8 and 9 shows results of stress on the frame and on the leaf spring. The showed stress is according to Von-Mises (Element-Nodal) [MPa].

Fig. 7 Results of displacement in the Z-direction [mm]
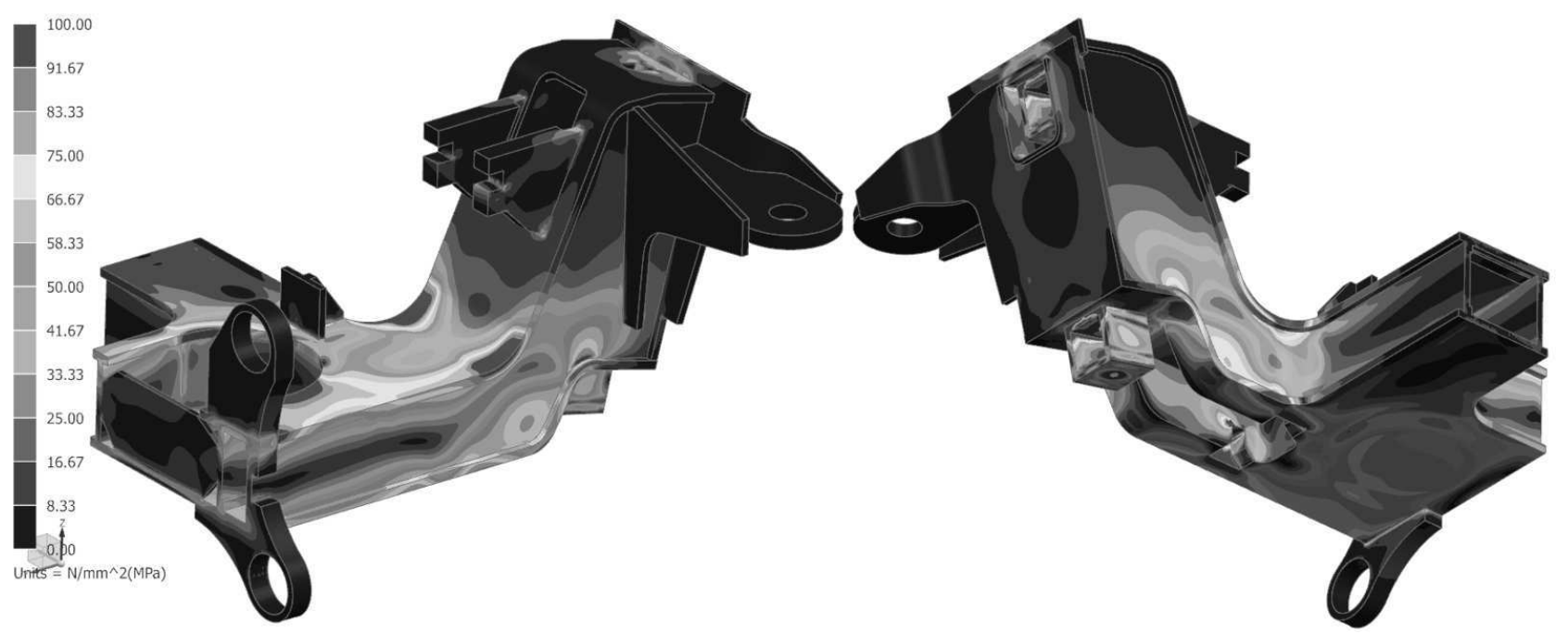

Fig. 8 Results of stress on the frame (Von-Mises, Element-Nodal) [MPa] 


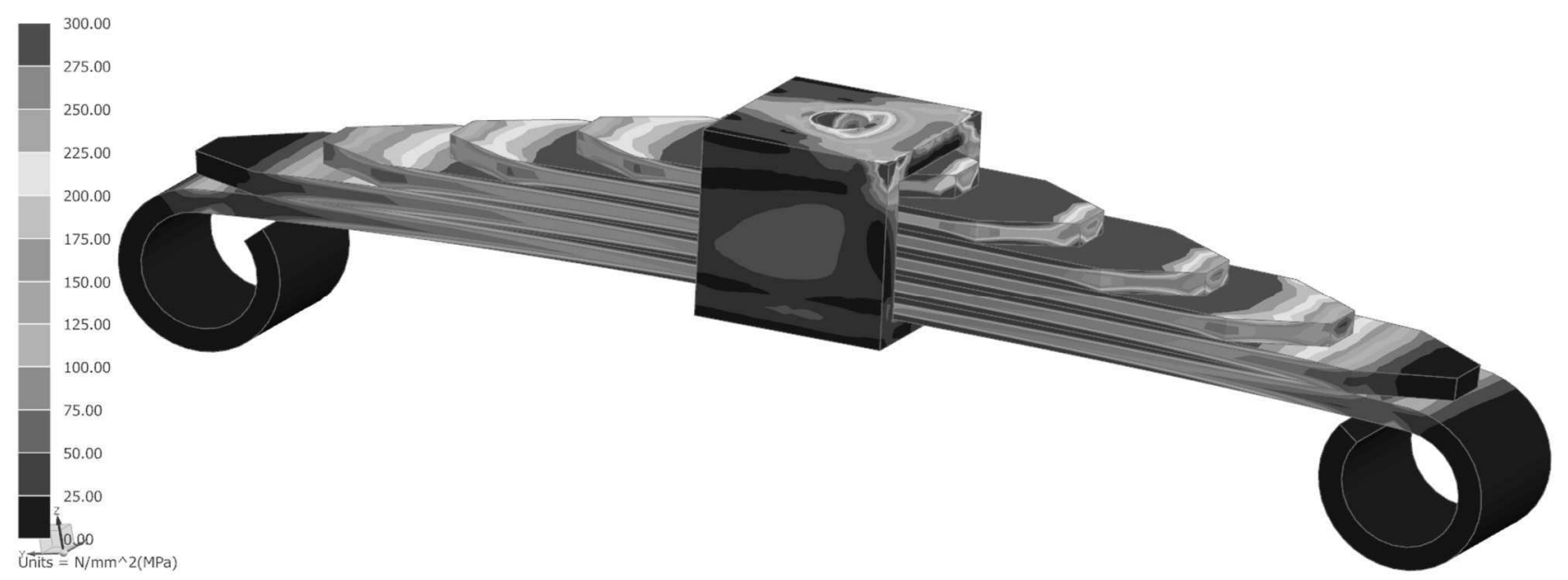

Fig. 9 Results of stress on the leaf spring (Von-Mises, Element-Nodal) [MPa]

\section{Experimental testing}

The experimental testing was performed on INOVA test bench. The QuantumX modular system with MX $1615 \mathrm{~B}$ modules with a sampling frequency of $5 \mathrm{~Hz}$ was used together with the HBM 1-LY11-6/120 strain gauges. The chassis was mounted on the rails and was loaded with the force by means of hydraulic cylinders (see Tab. 1). On the chassis there were placed strain gauges which sensed the values of the strain. 40 strain gauges were used for measuring. The strain gauge position was selected according to the FEA results. Measurement and evaluation were performed according to [7].
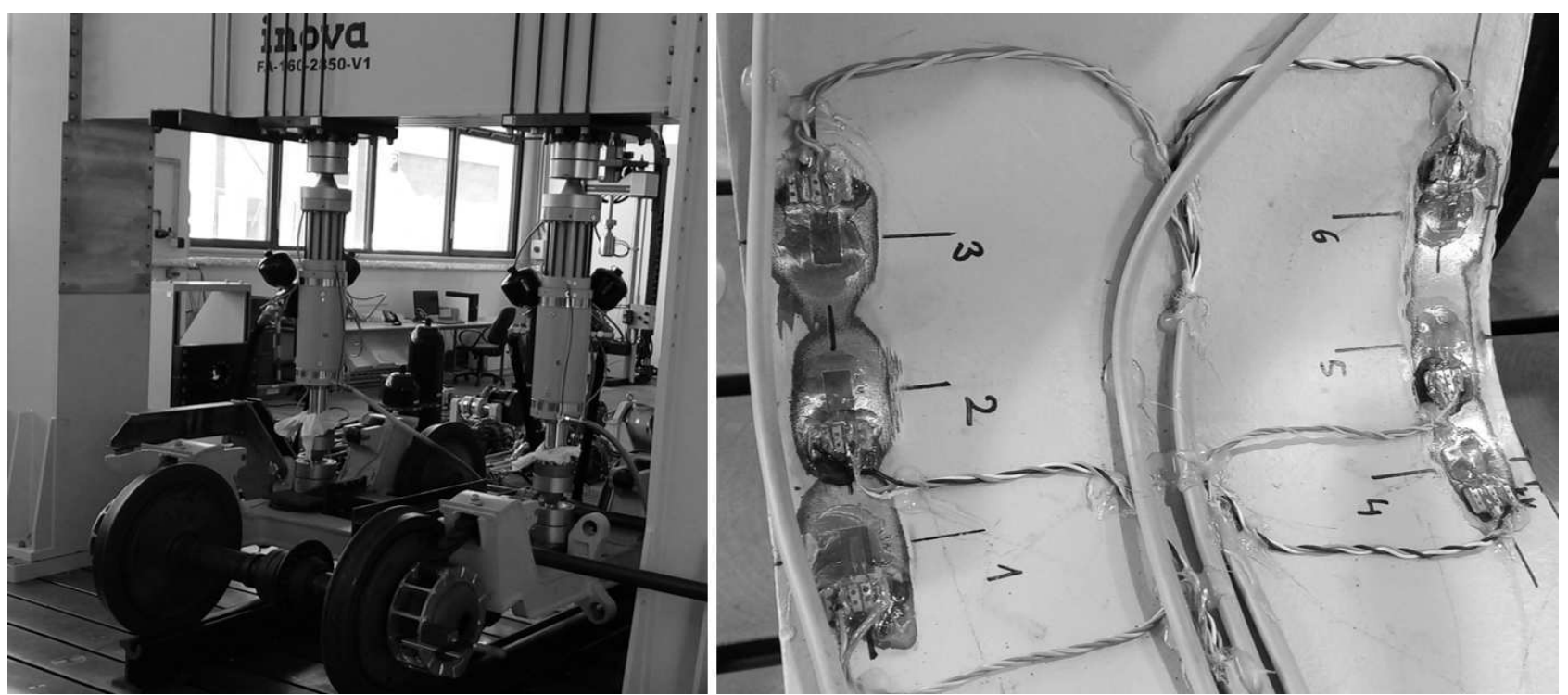

Fig. 10 Chassis on hydraulic machine and detail of the strain gauges

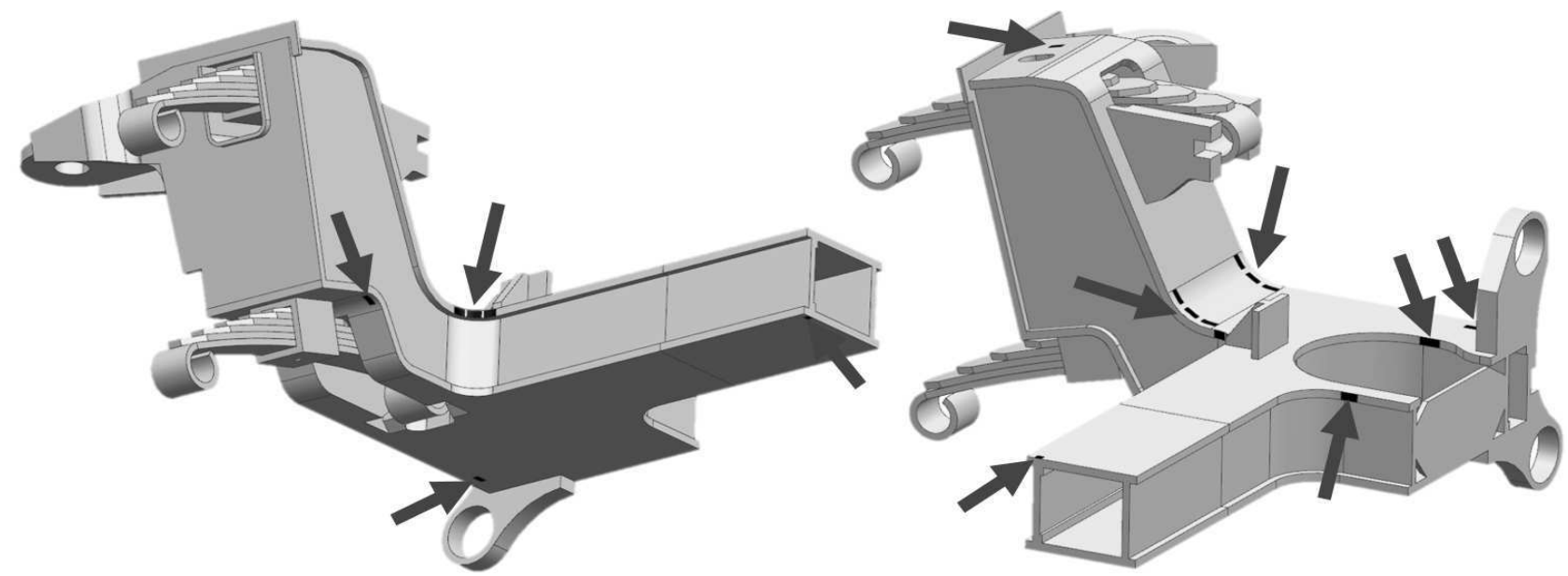

Fig. 11 Visualization of strain gauge position 


\section{Results from experimental testing}

The output from the measurement is the strain in the measured points. The measured strain measured from the strain gauges was recalculated to the uniaxial stress.

Where:

$$
\boldsymbol{\sigma}=\varepsilon \cdot \boldsymbol{E}[\boldsymbol{M P a}],
$$

$\sigma \ldots$ uniaxial stress $[\mathrm{MPa}]$

$\varepsilon \ldots$ strain $[-]$

E ... Young's modulus [MPa]

For example, for strain gauge T1:

$$
\sigma=\varepsilon \cdot E=0,000433 \cdot 210000=90,9[\mathrm{MPa}]
$$

\section{Comparison of the simulation and experimen- tal testing}

After processing FEA results and the experimental testing these results were compared. The values substracted from FEA and from the experimental measurement differ on average by $6.9 \%$, respectively by $5.6 \mathrm{MPa}$. The FEA results are usually higher than those measured during testing. Figure 12a) shows measured curves and figure $12 \mathrm{~b}$ ) reports measured values, calculated values and deviation.

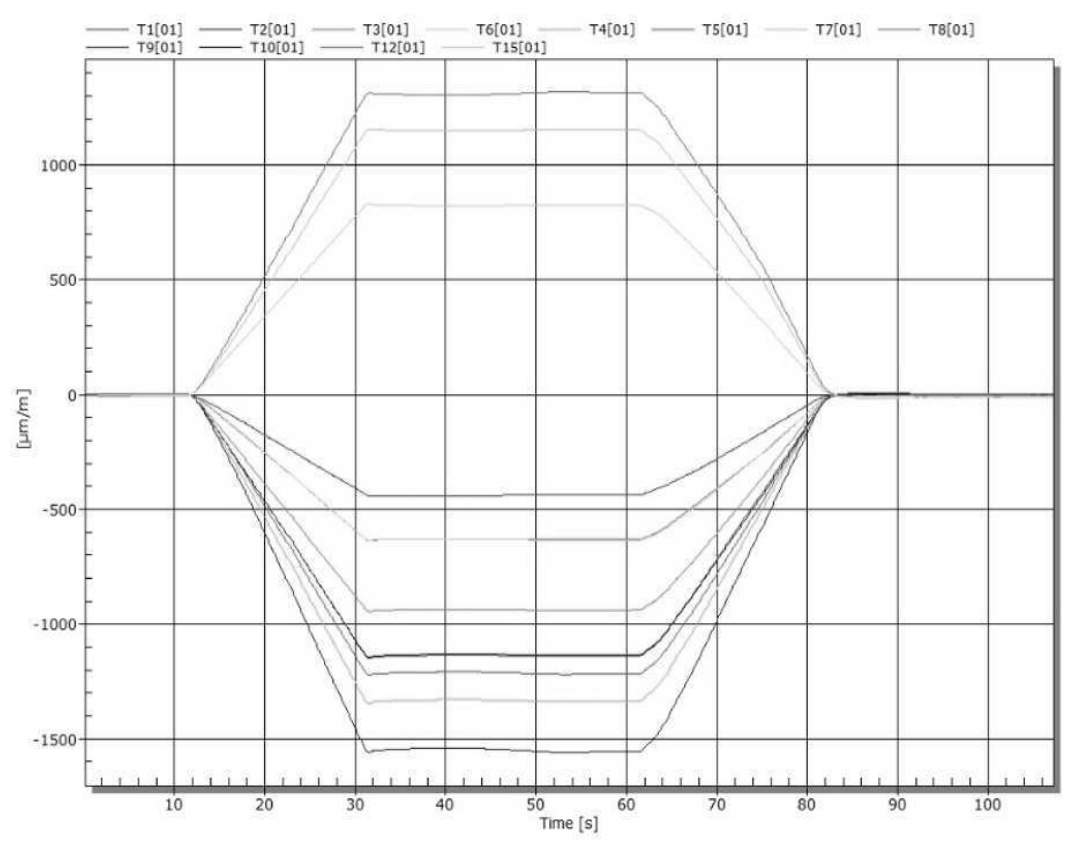

\begin{tabular}{|c|c|r|r|r|r|}
\hline \multirow{2}{*}{ No. } & $\boldsymbol{\varepsilon}$ EXP & REXP & \multicolumn{2}{|c|}{ RFEA } & \multicolumn{2}{|c|}{ Deviation } \\
\cline { 2 - 6 } & {$[\mu \mathrm{m} / \mathrm{m}]$} & {$[\mathrm{MPa}]$} & {$[\mathrm{MPa}]$} & {$[\%]$} & {$[\mathrm{MPa}]$} \\
\hline T01 & -432.0 & -91 & -95 & $4 \%$ & 4 \\
\hline T02 & -432.4 & -91 & -98 & $8 \%$ & 8 \\
\hline T03 & -236.7 & -50 & -53 & $6 \%$ & 3 \\
\hline T04 & -500.2 & -105 & -100 & $5 \%$ & 5 \\
\hline T05 & -456.6 & -96 & -94 & $2 \%$ & 2 \\
\hline T06 & -236.5 & -50 & -49 & $2 \%$ & 1 \\
\hline T07 & 432.1 & 91 & 97 & $7 \%$ & 6 \\
\hline T08 & 488.0 & $\mathbf{1 0 2}$ & $\mathbf{1 1 0}$ & $7 \%$ & 8 \\
\hline T09 & -164.4 & -35 & -30 & $15 \%$ & 5 \\
\hline T10 & -564.3 & -118 & -113 & $5 \%$ & 5 \\
\hline T11 & -604.8 & -127 & -131 & $3 \%$ & 4 \\
\hline T12 & -364.7 & -77 & -75 & $2 \%$ & 1 \\
\hline T13 & -433.7 & -91 & -100 & $9 \%$ & 9 \\
\hline T14 & -508.4 & -107 & -104 & $2 \%$ & 3 \\
\hline T15 & 324.3 & $\mathbf{6 8}$ & $\mathbf{6 3}$ & $8 \%$ & 5 \\
\hline
\end{tabular}

Fig. 12 a) Recording from few of the strain gauge, b) presentation of few results

\section{Conclusion}

The low-floor narrow-track revolving tram chassis was designed according to EN 13749: 2011 [3]. The frame of the chassis was subjected to FEA and to experimental testing. Based on FEA the places were chosen where the strain was measured which was then recalculated to the uniaxial stress. During comparison of FEA and experimental testing results an average variance of $6.9 \%$, respectively, 5.6 MPa was found (see Fig. ).

\section{Acknowledgements}

Authors of the work presented herein gratefully acknowledge the support in the form of the institutional funding for long-term strategic development of the University of West Bohemia provided by the Ministry of Education of the Czech Republic.

\section{References}

[1] HELlER, P., ČEJKA, B., TRPÁK, L. 2016). Study of Machine for Testing of the Traction Drive of Railway Vehicles. In Book of Procee- dings of 57th International Conference of Machine Design Departments. Plzeň: TYPOS, tiskařské závody, s.r.o., Plzeň, 2016. s. 41-48. ISBN: 978-80-261-0609-8

[2] HELLER, P., ČEJKA, B., TRPÁK, L. Test bench for testing of the traction drive of railway vehicles. MM Science Journal, 2016, roč. 2016, č. November, s. 1292-1296. ISSN: 1803-1269

[3] EN 13749:2011, Railway applications - Wheelsets and bogies - Method of specifying the structural requirements of bogie frames

[4] BLÁHA, P., HELLER, P. Trakčni podvozek pro tramvajová vozidla. Utility model 27 595, Praha, 2014.

[5] ZIENKIEWICZ, O. C., and ROBERT L. TAYLOR. The Finite Element Method. Oxford: Butterworth-Heinemann, 2000. Print.

[6] Soboyejo, Woley. Mechanical Properties of Engineered Materials. New York: Dekker, 2003. Print. 
[7] Figliola, Richard S., and Donald E. Beasley. Theory and Design for Mechanical Measurements. Hoboken: John Wiley \& Sons, 2015. Print.

[8] ŠŤASTNIAK, P., SMETANKA L., MORAVČÍK M. (2017) Development of Modern Railway Bogie for Broad Track Gauge - Bogie Frame Assessment In: Manufacturing technology: journal for science, research and production. - ISSN 1213-2489. - Vol. 17, No. 2 (2017), pp. 250-256, No. of acticle: MT201745.

[9] CHVAL, Z., RAZ, K., CECHURA, M. Analysis of stress distribution in the forging press, In: 26th DAAAM International Symposium on Intelligent Manufacturing and Automation, Volume 2015January, 2015, Pages 488-493, DAAAM 2015; University of Zadar, Zadar; Croatia; Code 123540;

[10] PATEK, M., MIČIAN, M., SLÁDEK, A., KADÁS̆, D., Numerical Analysis of T-Joint Welding with Different Welding, In: Manufacturing technology: journal for science, research and production. - ISSN 1213-2489. - Vol. 16, No. 1 (2016), pp. 234-238, No. of acticle: M201648.

[11] CHVAL, Z., SEDLACEK, F., KEMKA, V., Usage of FEM Simulations in Design of Piping Systems, In: Manufacturing technology: journal for science, research and production. - ISSN 1213-2489. - Vol. 17, No. 4 (2017), pp. 469-473, No. of acticle: MT201784.

[12] RAZ, K., HORA, J., PAVLATA, P., Unconventional Materials Usage in Design of Vehicle Bodies In: Manufacturing technology: journal for science, research and production. - ISSN 12132489. - Vol. 17, No. 5 (2017), pp. 823-827, No. of acticle: MT2017150.

[13] ŠPIRK S., The Collision of Unbelted Passenger with Assessment of Various Vehicle Interior, In: Manufacturing technology: journal for science, research and production. - ISSN 1213-2489. Vol. 17, No. 6 (2017), pp. 962-969, No. of acticle: M2017187. 